\title{
A Marketing Plan Proposal through Consumer Analysis: Focusing on the Scuba Diving Market
}

\author{
Hye-Kyung Baek ${ }^{1}$, Keun-Hyuk Hong ${ }^{2}$, and Hwa-yeol Choi ${ }^{3 *}$ \\ ${ }^{1}$ Professor, Department of Sports Industry, Jeju International University., Jeju-si, \\ Jeju-do, South Korea \\ ${ }^{2} \mathrm{Ph}$. D. Candidate, in department of physical education graduate school, Jeju \\ International University., Jeju-si, Jeju-do, South Korea \\ ${ }^{3}$ Professor, Department of Aviation Service Management Jeju International \\ University, South Korea \\ 3*hwayeol@hanmail.net
}

\begin{abstract}
The purpose of this study is to examine the possibility of scuba diving market applied to marketing theory. It is aimed to suggest a method of use to establish marketing strategy for scuba diving management by exploring the relationship between scuba diving consumers' lifestyle, scuba diving satisfaction, scuba diving equipment purchase decision factors, scuba diving consumer's lifestyle, and scuba diving satisfaction. To achieve this goal, 843 scubadiving consumers were surveyed by 843 male and female scuba-diving customers who use scuba-diving resorts and specialty stores nationwide. The analysis results by participation type are as follows As for the frequency of participation, 2-3 times a month was the most frequent with $41.2 \%$. In terms of experience, those with less than 3-7 years of experience accounted for the most, and those with less than 3 years of experience accounted for $33.3 \%$. As for the classification level, the beginner course level was the most at 40.9\%. As for companion type, co-workers, friends, and seniors and juniors were the highest at 34.8\%. For the purpose of participation, maintenance of health was the highest at $14.9 \%$.
\end{abstract}

Keywords: Scuba diving, Consumer, Consumer analysis, Marketing, Scuba diving market

\section{Introduction}

In Korea, interest in marine leisure sports is gradually increasing due to the geographical environment surrounded by the sea [1]. Marine leisure sports are only at the beginning stage in Korea, but they can be said to be sports activities with very high potential. In light of this trend, special interest and research on Korea's marine-related industries and policies, which have natural resources. It goes without saying what is needed, and it is a natural concept that marine leisure sports will be activated, and it can be said that it is very natural [2].

In particular, among marine leisure sports, scuba diving is a representative leisure sport that can be enjoyed as a leisure, and the natural environment such as the sea, various islands, and inland rivers and lakes provide an excellent environment for enjoying scuba diving.

Article history:

Received (September 18, 2020), Review Result (October 21, 2020), Accepted (December 6, 2020)

JARR

Copyright (C) 2021 Global Vision Press (GV Press) 
According to the recent scuba diving market, those who have been attracted to scuba diving, even in economic recession, continue to participate in diving activities. And they are more likely to experience scuba diving due to the perception that it is a luxury leisure sport [3]. However, despite the increasing number of scuba diving consumers, it is still relatively small compared to other sports and marketing research for these companies is insufficient, making it difficult to activate scuba diving.

This study aims to provide practical marketing implications in the scuba diving market through analysis of customers' perceptions of starting scuba diving.

\section{Theoretical background}

\subsection{Overview of scuba diving}

It is estimated that the first human diving was around 5000 B.C. At that time, it was conducted as a diving activity to get food and curiosity about the sea. Over the years, it was used for military purposes to install and destroy underwater structures, but in recent years, it has developed into a form of leisure sports for health promotion and leisure.

\subsection{Definition of scuba diving}

The meaning of the term scuba (Self Contained Underwater Breathing Apparatus: SCUBA) can be interpreted as an underwater self-breathing device, in other words, a device that stores the gas that the diver will breathe underwater. That is, scuba diving refers to diving in which underwater self-breathing equipment is worn and active underwater. It is a term derived from the distinction from the sea level supply type (helmet diving, a type in which the diver dives non-independently connected to the air hose supplied from the surface). In scuba diving, compressed air is put in a metal canister called a cylinder or a tank, and it is carried on his back to breathe. The high pressure air in the tank is adjusted to be equal to the ambient pressure for breathing by a regulator attached to the tank. Sometimes scuba diving is used in the same sense as recreational diving or sports diving. These terms can be used only with scuba diving as a hobby. In addition, the term skin diving is often used, which refers to diving without the aid of breathing equipment [4].

\subsection{Curriculum of Scuba diving}

There are theories and techniques that you must learn to enjoy scuba diving safely. How to handle and use the equipment, problems and solutions caused by pressure, how to prevent accidents, buoyancy control, and basic skills must be continuously learned over a long period of time.

The government's legal regulations are quite inadequate for the act of scuba diving itself. In foreign countries, however, diving activities are rarely possible without the qualifications of internationally recognized organizations. Recently in Korea, the government has not lent scuba diving activities and scuba diving equipment without such a license, and in order to obtain a license, you must take lessons from instructors belonging to organizations that provide professional diving education

Since they issue certifications based on certain standards, they must have the theories and skills necessary to obtain a certification at a certain level or higher. The qualifications of these organizations are divided into several levels according to the level of theory and skill. 
In the beginner or introductory course, such as the Scuba Diver or Open water Diver, you will learn the theories and skills necessary for diving activities, and the person who is certified in this course must be aware that they can work in similar environments they have received and only perform at a trained level. In the absence of a supervisor, divers who engage in diving activities above their own level go beyond the limits allowed by their credentials. In order to increase one's ability and have the opportunity to engage in various activities, one needs to gain experience elsewhere than in the ideal environment of being trained in the beginner's course.

The intermediate course is usually called the Advanced Scuba Diver course, and the intensive training process, especially focusing on a certain area, is called a special course. Examples of special processes include shipwreck diving, cave diving, ice diving, deep-sea diving, search and rescue diving, Night diving, underwater photography, underwater direction finding and nitrox diving.

These courses are usually divided into three stages: theoretical education, practical education, and field adaptation. First, after acquiring the necessary knowledge in theoretical education, diving skills will be trained in restricted areas similar to swimming pools, and practical training will be given the opportunity to practice the skills learned in restricted areas in real field waters such as calm seas and rivers. Of course, the written test of the theory and the instructor's technical evaluation are conducted together during this process, and the instructor's judgment is to issue a certificate of the organization. Beginner and intermediate process while diving and diving skills are much increased activity in various fields who want to be an expert divers is advanced. Master scuba diver role as a diving here to challenge the process of technology leaders, not only learn about [5]. In addition to the instructor's education assistant instructor (assistant instructor) to help and scuba diving instructor and (instructor) dive to resorts, diving activities in the field. Master is diving career, such as (divemaster) and people.

\section{Status of scuba diving market}

The number of consumers who receive education from domestic and foreign scuba diving professional educational organizations and enter scuba diving is increasing every year, and the desire for educational facilities and equipment is increasing accordingly.

\subsection{Scuba diving professional education organization}

Scuba diving professional education organizations currently operating at home and abroad are as follows:

The British Sub Aqua Club (BSAC) was founded on October 15 in London, England, as the world's first diving organization, with the aim of conducting safer and scientific underwater exploration in 1953. The name of the group was borrowed from the place where it was founded, and the name "The British Sub-Aqua Club" was used, and BSAC was founded by Oscar Gugen with the help of Peter Small [6].

The Confederacy Mondale des Activities Subqueries (CMAS) and the Korea Underwater Association (KUA) are the World Water Federation, which was founded on September 28, 1959 by the Association of 15 countries under the leadership of Jacques Yves Cousteau. Unlike ordinary educational organizations, CMAS is an international organization in which underwater associations of each country join as a member group. That is, each member group is an educational organization [7]. 
KUA was founded in 1968 to promote national sports and promote healthy and cheerful social atmosphere by spreading pin swimming and underwater sports to the people, as well as to guide affiliated organizations and nurture outstanding athletes to promote national prestige and contribute to the development of national sports. Korea has been issuing CMAS certification to those who joined the World Federation in 1982 and have completed the KUA's education at the same time [8].

IANTD (International Association of Nitrox and Technical Divers) is the world's first Nitrox and Technical Diving Training Institute founded by Dick Rutkowski, a global expert in mixed gas and re-pressure chambers [9].

The International Diving Educators Association (IDEA) was originally established as the Florida Skin Divers Association in 1952 and has been spread to the Bahamas, Kaman Islands, Jamaica, Bermuda, Antils, and Barshaero, to the extent that there were more Florida Scuba Association educators abroad than in the United States by 1978. Around this time, members of the committee concluded that the Florida Scuba Diving Association had grown more than the Florida Scuba Diving Association, and created a new logo and new drug center to create IDEA [10].

The Korea Underwater Diving Association (KUDA), which was launched in 1979, is actively engaged in activities with the intention of loving advanced oceans through education, research, training, and technology development on diving, cultivating mind and body through diving, and strengthening mutual friendship among divers. At the time of its foundation, it obtained approval from the Ministry of Education under the Act on the Establishment and Operation of Certified Corporations, and the Ministry of Culture and Sports was transferred to the Ministry of Culture, Sports and Tourism under the relevant Act as amended on March 20, 1982, and is currently the only government-recognized corporation [11].

The National Association of Skin Diving Schools (NASDS) has been active, starting with the first retail union in the diving industry in 1962, creating Club Aquarius in 1964, and establishing the first instructor college in 1968 [12].

The National Association of Underwater Institutions (NAUI) was renamed NAUI by Neil Hess in 1959 and reorganized into the first public diving group to provide instructor training [13].

The Professional Association of Living Institutions (PADI) began in 1966 when a group of four instructors from other organizations formed a new group to innovate their training [14].

The Professional Living Instruments Corporation (PDIC) was founded in 1969 by Ed Brolley, who led diving training in the United States in the 1960s, in Monterey, California, the home of diving, to initiate systematic instructor training [15].

SDD International (Safe Living Development International) is a new educational organization in Korea that puts top priority on safety, service and honor [16]. It is an organization created by Scubapro, a diving company with an international network of organizations such as Germany, Belgium, Spain, Canada, Sweden, Britain, Austria, Australia and Japan [17].

The Scuba School International (SSI) is a scuba diving organization founded in the United States in 1970 by current chairman Clarke [18].

TDI/SDI (Technical Living/Scuba Living International) was founded in April 1994 by Brett Gilliam and Mitch Skagg, well-known as pioneers of technical diving, an educational institution that goes beyond the scope of general sports diving [19].

\section{Sports marketing strategy and consumer segmentation}


Sports marketing constitutes individual activities and organizational activities that promote satisfactory exchange relationships through creation, distribution, promotion, promotional activities, customer service, customer care and pricing, as well as marketing of sports in a dynamic environment.

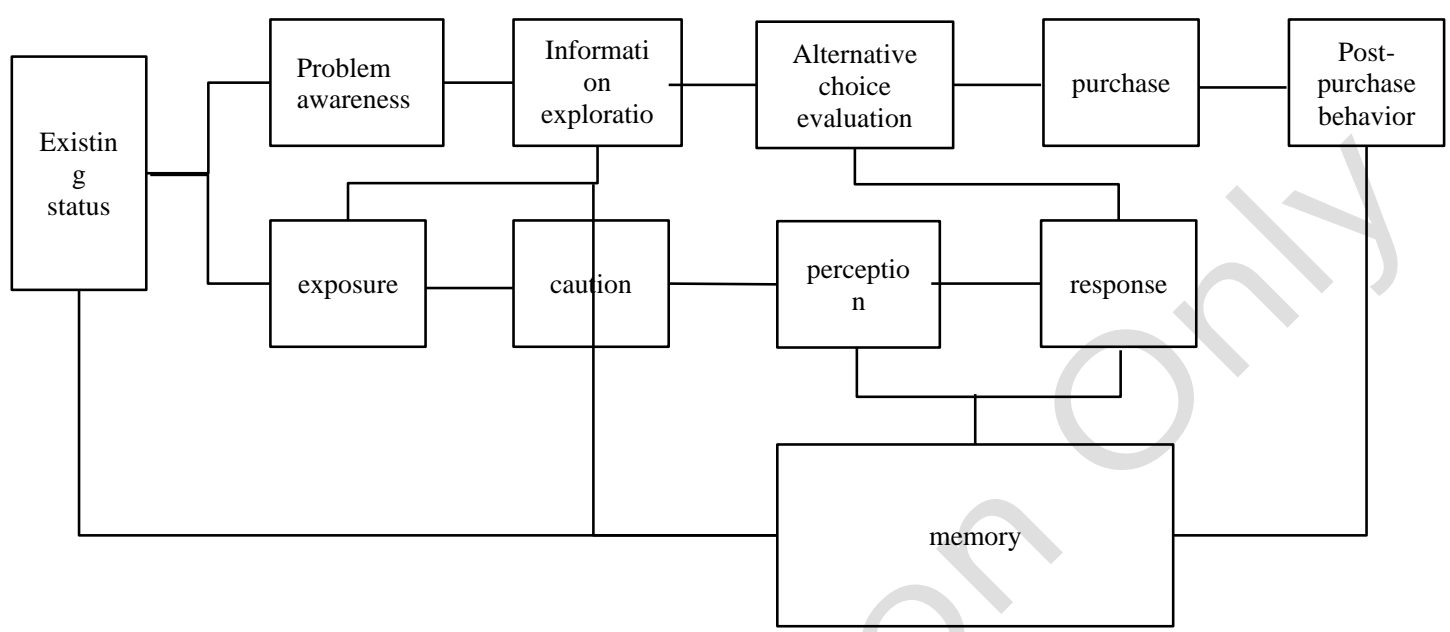

Figure 1. Consumer decision-making and information processing processes [20]

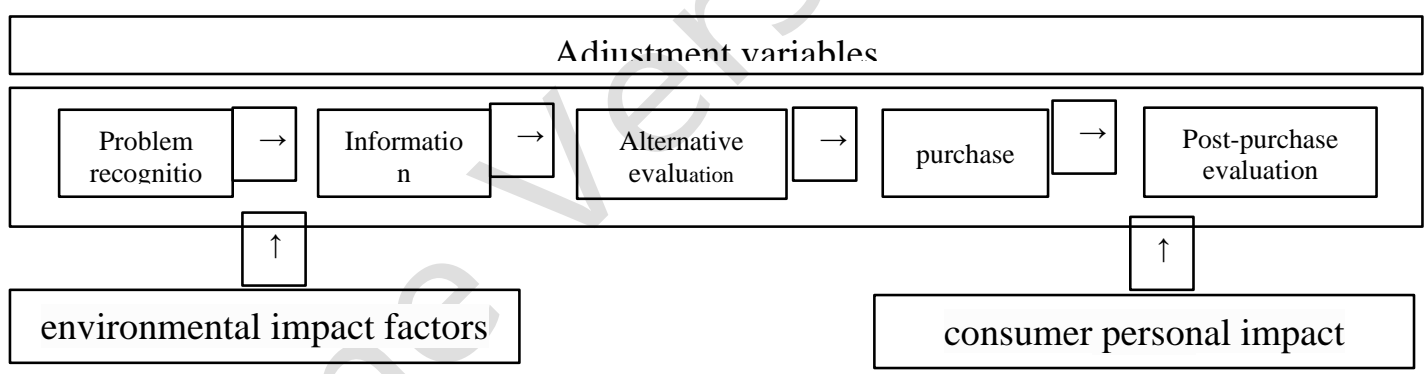

Figure 2. General model of purchasing decisions [21]

\subsection{Process of planning for sports marketing}

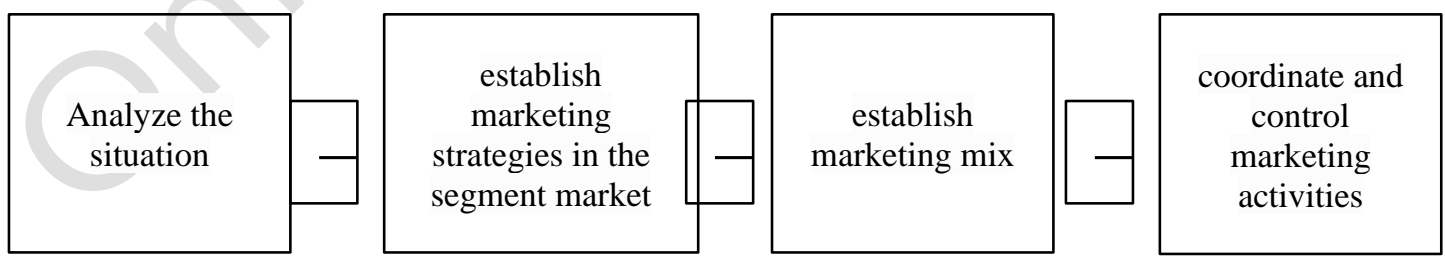

Figure 3. Marketing planning course [22]

\section{Research methods}

\subsection{Subject to research}


The subject of this study is a population of scuba diving consumers who are using scuba diving resorts and specialty stores registered with scuba diving educational organizations located nationwide, and a total of 1000 people were selected as the survey target by a random sampling method. Among the collected questionnaires, 843 questionnaires were surveyed after excluding data that were judged to have responded unfaithfully or whose survey contents were partially omitted.

Table 1. Characteristics of scuba diving participation types of subjects studied

\begin{tabular}{|c|c|c|c|}
\hline Type of participation & Division & $\mathrm{N}(\%)$ & SUM(\%) \\
\hline $\begin{array}{l}\text { frequency of } \\
\text { participation }\end{array}$ & $\begin{array}{l}\text { more than four times a week } \\
1 \text { to } 3 \text { times a week } \\
\text { two to three times a month } \\
\text { less than two times a month }\end{array}$ & $\begin{array}{c}60(7.1) \\
189(22.4) \\
347(41.2) \\
247(29.3)\end{array}$ & $843(100)$ \\
\hline experience & $\begin{array}{l}\text { Less than three years } \\
\text { Less than } 3 \text { to } 7 \text { years } \\
\text { Less than } 7 \text { to } 11 \text { years } \\
11 \text { years or more }\end{array}$ & $\begin{array}{l}281(33.3) \\
303(35.9) \\
138(16.4) \\
121(14.4)\end{array}$ & $843(100)$ \\
\hline classification & $\begin{array}{l}\text { beginner's process level } \\
\text { intermediate course level } \\
\text { Advanced Course Level }\end{array}$ & $\begin{array}{l}345(40.9) \\
242(28.7) \\
256(30.4)\end{array}$ & $843(100)$ \\
\hline companion & $\begin{array}{c}\text { one's family and relatives } \\
\text { colleagues, friends, seniors and } \\
\text { juniors } \\
\text { a member of a club } \\
\text { Leader }\end{array}$ & $\begin{array}{c}76(9.0) \\
293(34.8) \\
226(26.8) \\
248(29.4)\end{array}$ & $843(100)$ \\
\hline $\begin{array}{c}\text { purpose of } \\
\text { participation }\end{array}$ & $\begin{array}{c}\text { To maintain and promote health } \\
\text { To acquire motor skills } \\
\text { for socializing or interpersonal } \\
\text { relations. } \\
\text { To enjoy life } \\
\text { To relieve stress } \\
\text { for the utilization of future jobs }\end{array}$ & $\begin{array}{l}126(14.9) \\
71(8.4) \\
54(6.4) \\
422(50.1) \\
119(14.1) \\
51(6.1)\end{array}$ & $843(100)$ \\
\hline
\end{tabular}

\section{Conclusions}

The purpose of this study is to examine the possibility of scuba diving market applied to marketing theory and to suggest a method of use to establish marketing strategy for scuba diving management by exploring the relationship between scuba diving consumers' lifestyle, scuba diving satisfaction, scuba diving equipment purchase decision factors, and scuba diving consumer's lifestyle and scuba diving satisfaction. To achieve this goal, 843 scuba-diving consumers were surveyed by 843 male and female scuba-diving customers who use scubadiving resorts and specialty stores nationwide. As a result of frequency analysis of the data, the following results were found.

First, in terms of lifestyle differences between demographic variables and scuba diving participation types, innovation pursuit types were high among management men with fouryear college degrees or more, who earned more than 3.5 million won a month, and qualifications for advanced courses with more than 11 years of experience, and colleagues, friends, seniors and juniors, and consumers who wanted to use them as future jobs. The trendseeking type was high among unmarried women in their 20s with a student or professional college degree, more than four times a week, less than three years of experience, and consumers who participated in social or personal relationships by scuba diving with colleagues, friends, seniors and juniors. 
Second, in relation to lifestyle and scuba diving satisfaction according to scuba diving participation type, health pursuit type and facility satisfaction were most related to the frequency of participation more than four times a week, health pursuit type and psychological satisfaction in one to three times a week, self-examining type and social satisfaction in two to three times a month, and innovation pursuit type and psychological satisfaction in less than two times a month. Self-examining and social satisfaction in less than three years of experience, self-examining and social satisfaction in less than three to seven years of experience, and social satisfaction in less than seven to eleven years of experience were most related to innovation pursuit and social satisfaction.

At the qualification level of the beginner course, self-examining type, social satisfaction, and intermediate course qualification level, health pursuit type, psychological satisfaction, and advanced course qualification level were most related to innovation pursuit type and social satisfaction. In scuba diving activities with family members and relatives, psychological satisfaction, self-examining and social satisfaction with colleagues, friends, and juniors, scuba diving activities with club members were most related to self-examining and social satisfaction, and in scuba diving activities with leaders.

For the purpose of maintaining and promoting health, self-examination, social satisfaction, and acquisition of athletic skills, the purpose of health pursuit, psychological satisfaction, social satisfaction, and interpersonal relationship was most related to the pursuit of health, social satisfaction, and the purpose of relieving stress for the purpose of self-examining, physical satisfaction, and social satisfaction.

Depending on the results of the frequency analysis, practical implications are as follows. The factor of participation frequency should be to give more marketing benefits to customers 2-3 times a month to obtain a lock-in effect. Since $70 \%$ of the customers are less than 7 years old, it is desirable to keep existing customers rather than creating new customers. Since the qualification level factor is similar to the beginner level and the advanced level, it is desirable to operate in both basic and advanced classes. The partner factor appears in the order of coworkers, friends, and club members rather than family members, so companies should actively promote social media community activities. The most important factor for participation was to enjoy life, which seems to indicate that scuba diving customers are pursuing the current YOLO. Therefore, it would be advantageous for companies to do YOLO marketing.

\section{References}

[1] Park Soo-Jjung, "Differences in motivation and satisfaction of participating water sports participants according to the events," A Master's Thesis Ewha Womans University Graduate School, (1996)

[2] Lee Joon-Hee and Choi Jeong-Do, "Current status and activation plan of marine leisure sports korea sports research," vol.14, no.2, pp. 425-436, (2003)

[3] Ko Hyun-Nam, "Relationship between skin and scuba participation level and immersion experience and health promotion lifestyle," Unpublished Master's Degree Thesis. Graduate School of Social Sports at Korea National Sport University, (1999)

[4] Lim Bong-Woo, "A case study on the meaning of relationships with others in scuba activities," Korean Journal of Convergence Science, vol.9, no.3, pp.362-372, (2020)

[5] Korea Maritime and Ocean University Leports Center, "A scuba-diving course textbook,” (2020)

[6] http://www.bsac.co.kr

[7] http://www.cmaskorea.com

[8] http://www.kua.or.kr 
[9] http://www.iantd.co.kr

[10] http://www.idea-asia.com

[11] http://www.kuda.or.kr

[12] http://nasds-scuba.com

[13] http://www.naui.co.kr

[14] http://www.padi.com

[15] http://www.pdic.co.kr

[16] http://www.sddi.org

[17] http://www.sea.co.kr

[18] http://www.ssikorea.co.kr

[19] http://www.tdisdi.co.kr

[20] Lee Hak-Sik, "Consumer behavior 6th edition," Seoul: Jibhyeonjae, (2015)

[21] Seo Sung-Han, Kim Hyeong-Jae and Choi Hyeoun-Gyu, "Consumer behavior," Seoul: Park Youngsa, (2012)

[22] Chae Seo-il and Lee Sung-Ho, "Marketing 6th Edition,” Seoul: B\&M Books, (2017) 